\title{
Fracture of Femur in a Young Obese Individual With Type 2 Diabetes, Hypogonadism and Low Vitamin D: As in the Titanic We Are Only Seeing the Tip of the lceberg?
}

\author{
Mohamed H. Ahmed ${ }^{\mathrm{a}, \mathrm{c}}$, Bisoye F. Fagbohungbe ${ }^{\mathrm{b}}$, Jane Webber ${ }^{\mathrm{b}}$
}

\begin{abstract}
We report a case of a 42-year-old male with poorly controlled type 2 diabetes and body mass index (BMI) of $35 \mathrm{~kg} / \mathrm{m}^{2}$ who was admitted with fracture of right head of the femur after small fall from stepladder. Imaging of the pelvis in the form of an X-ray showed multi-fragmented fracture through trochanteric region of the right femur. His fracture was fixed with an intramedullary device. However, subsequent tests revealed low testosterone $(4.2 \mathrm{nmol} / \mathrm{L}$ and reference range $10-35 \mathrm{nmol} / \mathrm{L})$ and low vitamin $\mathrm{D}(13.2 \mathrm{nmol} / \mathrm{L}$ and reference range $>50$ ). His bone densitometry scan showed no evidence of osteoporosis. Furthermore, his diabetes control was poor with an average $\mathrm{HbA} 1 \mathrm{c}$ of $11 \%$ and he was also known to have background diabetic retinopathy. The combination of poor diabetes control, obesity, hypogonadism and low vitamin D may all have contributed to an increase in risk of fracture in association with simple fall in this young man. Obesity and type 2 diabetes are associated with hypogonadism and low vitamin D. In view of the high epidemic of diabetes and obesity, it is possible to suggest that there are large numbers of these individuals with high risk for fracture likely to be induced upon any mild degree of trauma. Furthermore, it is possible to suggest that obesity-induced fracture will increase the burden in orthopedic department and the current numbers of fractures related to obesity may represent the tip of iceberg. Our case report is unique as the fracture occurred in a young individual with all these metabolic disorders. Therefore, our case report illustrates the needs for close collaboration between orthopedic surgeons, general practioners and endocrinologists and importantly the need for robust methods for screening and risk stratifications.
\end{abstract}

Keywords: Obesity; Diabetes; Fracture and hypogonadism

Manuscript accepted for publication January 06, 2016

aDepartment of Medicine, Milton Keynes University Hospital NHS Foundation Trust, Eaglestone, Milton Keynes, Buckinghamshire, UK

bDepartment of Orthopaedic and Trauma, Milton Keynes University Hospital NHS Foundation Trust, Eaglestone, Milton Keynes, Buckinghamshire, UK ${ }^{\mathrm{c}}$ Corresponding Author: Mohamed H. Ahmed, Department of Medicine, Milton Keynes University Hospital NHS Foundation Trust, Eaglestone, Milton Keynes, Buckinghamshire, UK. Email: elziber@yahoo.com

doi: http://dx.doi.org/10.14740/jmc2402w

\section{Introduction}

Obesity is a common problem across the globe and represents a challenge for all health authorities. The prevalence of obesity in Europe is estimated to be $23 \%$ in women and $20 \%$ in men. Currently, there is no evidence that the prevalence of obesity is slowing down. For instance, by 2025 in UK, it is expected that $47 \%$ of men and $36 \%$ of women will be obese [1]. Several studies suggested that obesity is associated with decrease in bone mineral density (BMD) and increase in risk of bone fragility. In a study conducted by Fracture Liaison Service in Cambridge (UK) that involved 1,005 postmenopausal women $<75$ years of age presenting with a low trauma fracture, obesity was shown to be associated with significant risk of hip fractures, while the risk of fractures of the wrist was significantly less common [2]. Furthermore, a study from the Nottingham Fracture Liaison Service reported that obese subjects were more likely to fracture their ankle and upper arm, but were less likely to fracture their wrist [3]. The Global Longitudinal Study of Osteoporosis in Women (GLOW) showed that obesity is not protective against fracture in postmenopausal women and is associated with increased risk of ankle and upper leg fractures [4]. Obesity may also influence bone integrity through its impact on vitamin D and testosterone level. Several studies have shown that obesity is associated with low vitamin $\mathrm{D}$ and low plasma testosterone levels $[5,6]$. One serious consequence of obesity is development of insulin resistance and type 2 diabetes. Importantly, there is emerging evidence that diabetes has an impact on bone metabolism.

The Rotterdam Study showed that individuals with diabetes had an increased fracture risk, probably due to long-term complications associated with diabetes mellitus [7]. Importantly, in a meta-analysis by Vestergaard, it was shown that hip fracture risk increased in both type 1 and type 2 diabetes mellitus, whereas BMD increased in type 2 diabetes mellitus and decreased in type 1 diabetes mellitus [8]. Poor diabetes control is also associated with high risk of bone fracture. For instance, the Atherosclerosis Risk in Communities (ARIC) Study showed that type 2 diabetes was significantly and independently associated with increased risk of fracture especially those treated with insulin or those with $\mathrm{HbAlc} \geq 8 \%$ $(64 \mathrm{mmol} / \mathrm{L})$ as compared to those individuals with $\mathrm{HbA} 1 \mathrm{c}$ below $8 \%$ [9]. Furthermore, the Rotterdam Study data showed that poor glycemic control based on an HbA1c cut-off of $7.5 \%$ 


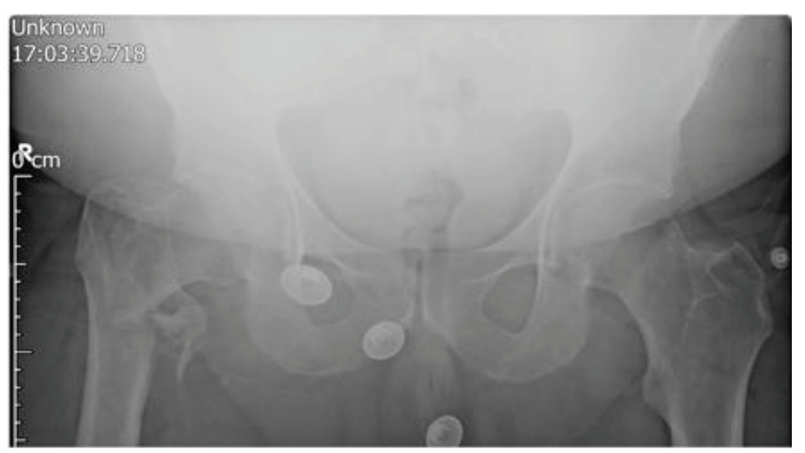

Figure 1. X-ray pelvis showing a right intertrochanteric neck of femur fracture.

$(58 \mathrm{mmol} / \mathrm{L})$ in type 2 diabetes was associated with higher all types of fracture risk [10].

\section{Case Report}

We report a case of a 42-year-old male with poorly controlled type 2 diabetes (diagnosed 10 years ago) and body mass index (BMI) of $35 \mathrm{~kg} / \mathrm{m}^{2}$ who was admitted with fracture of right head of the femur after small fall from stepladder. Imaging of the pelvis in the form of an X-ray showed multi-fragmented fracture through trochanteric region of the right femur (Fig. 1). His investigations during the time of admission to our hospital showed normal renal, liver and thyroid function. His chest Xray showed clear lung field and normal heart size. His ECG showed he was in sinus rhythm. Furthermore, his diabetes control was poor with an average $\mathrm{HbAlc}$ of $11 \%$ and he was also known to have background diabetic retinopathy. He suffered from erectile dysfunction for around 4 years but he did not seek medical help and this was revealed during his consultation with endocrinologist during the treatment for his fracture. His family history showed the presence of diabetes and hypertension without evidence of family history of osteoporosis. He was treated with metformin 2,000 mg per day, gliclazide 320 $\mathrm{mg}$ per day and sitagliptin $100 \mathrm{mg}$ per day. He was switched to insulin therapy and advised to continue with metformin therapy as well. His fracture was fixed with an intramedullary device (Fig. 2). However, subsequent tests revealed low testosterone $(4.2 \mathrm{nmol} / \mathrm{L}$ and reference range $10-35 \mathrm{nmol} / \mathrm{L})$ and low vitamin $\mathrm{D}(13.2 \mathrm{nmol} / \mathrm{L}$ and reference range $>50)$. During his hospital stay, he was commenced in vitamin D replacement. His bone densitometry scan showed no evidence of osteoporosis. After successful treatment of his fracture, he was given physiotherapy and then discharged. He was referred to the diabetes and endocrinology outpatients for optimization of his diabetes control and treatment of hypogonadism.

\section{Discussion}

Our case report showed that the presence of obesity, poorly controlled diabetes, low vitamin D and hypogonadism is associated with increased risk of bone fracture. Importantly,

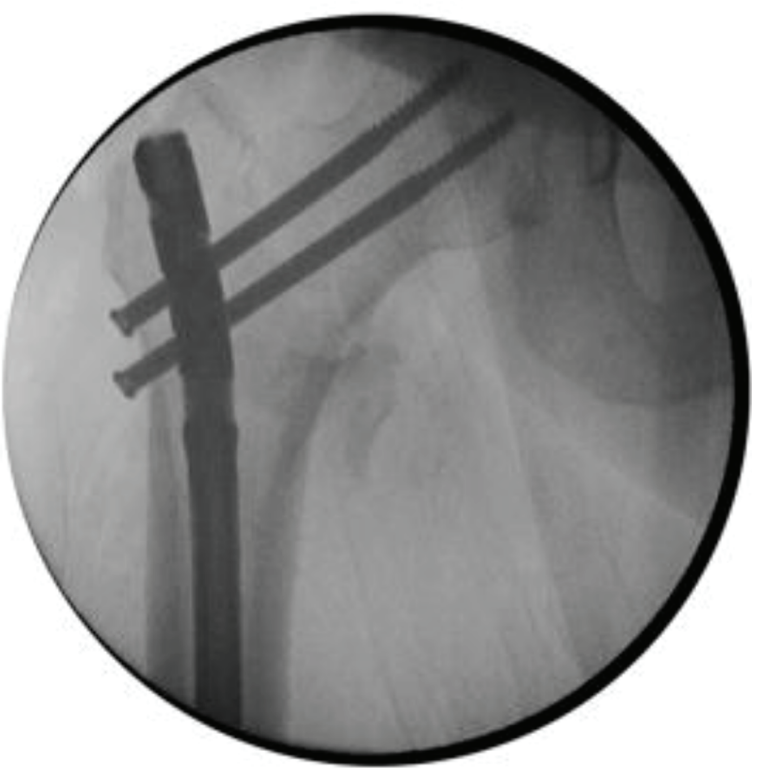

Figure 2. Fracture of right neck of femur fixed with intramedullary nail.

this can increase risk of fracture in young individuals. Interestingly, the bone density scan was normal. Cross-sectional epidemiological studies have found that patients with type 2 diabetes mellitus have a higher incidence of fragility fractures despite normal or elevated BMD [3, 8-10]. This is likely to be explained by the fact that type 2 diabetes induces deterioration of bone microarchitecture leading to a porous skeleton susceptible to fracture. Furthermore, it was shown that cortical porosity is specific to those with type 2 diabetes patients that have a fracture $[11,12]$. In addition, conventional diagnostics such as DXA measurements and the current fracture risk assessment tool (FRAX) risk prediction algorithm for estimating risk of osteoporotic fractures are not sufficient in individuals with diabetes $[11,12]$.

In view of the increased prevalence of diabetes and obesity, it is possible to predict that obesity-induced fracture will increase the burden in orthopedic department. It is very difficult to predict how this epidemic will affect the orthopedic service, in particular in the absence of robust screening method and also the absence of diagnostic tools for osteoporosis in individuals with diabetes. Another problem in the horizon, detection of such individuals at young age is vital, as he is likely to need hip replacement twice assuming that he lives up to 85 years old. Therefore, our case report illustrates the needs for close collaboration between orthopedic surgeons, general practioners and endocrinologists not only in treatment of obesity, diabetes, osteoporosis, fracture and hypogonadism but also the need to establish robust methods for screening and risk stratifications.

\section{Conclusion}

In individuals with diabetes, obesity, low vitamin $\mathrm{D}$ and low testosterone, the risk of fracture is difficult to be estimated es- 
pecially in young individuals. Such unfortunate individuals can present with complications such as fracture of the neck of the femur. Therefore, aggressive treatments of risk factors are necessary in all patients.

\section{Conflict of Interest}

None.

\section{Funding}

None.

\section{Author Contributions}

All authors equally contributed to this paper with conception and design of the study, literature review and analysis, drafting and critical revision and editing, and final approval of the final version.

\section{References}

1. Finucane MM, Stevens GA, Cowan MJ, Danaei G, Lin JK, Paciorek CJ, Singh GM, et al. National, regional, and global trends in body-mass index since 1980: systematic analysis of health examination surveys and epidemiological studies with 960 country-years and 9.1 million participants. Lancet. 2011;377(9765):557-567.

2. Premaor MO, Pilbrow L, Tonkin C, Parker RA, Compston J. Obesity and fractures in postmenopausal women. J Bone Miner Res. 2010;25(2):292-297.

3. Ong T, Sahota O, Tan W, Marshall L. A United Kingdom perspective on the relationship between body mass index (BMI) and bone health: a cross sectional analysis of data from the Nottingham Fracture Liaison Service. Bone.
2014;59:207-210

4. Compston JE, Watts NB, Chapurlat R, Cooper C, Boonen $\mathrm{S}$, Greenspan S, Pfeilschifter J, et al. Obesity is not protective against fracture in postmenopausal women: GLOW. Am J Med. 2011;124(11):1043-1050.

5. Orwoll E, Lambert LC, Marshall LM, Blank J, BarrettConnor E, Cauley J, Ensrud K, et al. Endogenous testosterone levels, physical performance, and fall risk in older men. Arch Intern Med. 2006;166(19):2124-2131.

6. Grethen E, McClintock R, Gupta CE, Jones R, Cacucci BM, Diaz D, Fulford AD, et al. Vitamin D and hyperparathyroidism in obesity. J Clin Endocrinol Metab. 2011;96(5):1320-1326.

7. de L, II, van der Klift M, de Laet CE, van Daele PL, Hofman A, Pols HA. Bone mineral density and fracture risk in type-2 diabetes mellitus: the Rotterdam Study. Osteoporos Int. 2005;16(12):1713-1720.

8. Vestergaard P. Discrepancies in bone mineral density and fracture risk in patients with type 1 and type 2 diabetes--a meta-analysis. Osteoporos Int. 2007;18(4):427-444.

9. Schneider AL, Williams EK, Brancati FL, Blecker S, Coresh J, Selvin E. Diabetes and risk of fracture-related hospitalization: the Atherosclerosis Risk in Communities Study. Diabetes Care. 2013;36(5):1153-1158.

10. Oei L, Zillikens MC, Dehghan A, Buitendijk GH, CastanoBetancourt MC, Estrada K, Stolk L, et al. High bone mineral density and fracture risk in type 2 diabetes as skeletal complications of inadequate glucose control: the Rotterdam Study. Diabetes Care. 2013;36(6):1619-1628.

11. Patsch JM, Burghardt AJ, Yap SP, Baum T, Schwartz AV, Joseph GB, Link TM. Increased cortical porosity in type 2 diabetic postmenopausal women with fragility fractures. J Bone Miner Res. 2013;28(2):313-324.

12. Burghardt AJ, Issever AS, Schwartz AV, Davis KA, Masharani U, Majumdar S, Link TM. High-resolution peripheral quantitative computed tomographic imaging of cortical and trabecular bone microarchitecture in patients with type 2 diabetes mellitus. J Clin Endocrinol Metab. 2010;95(11):5045-5055. 